Niniejsza publikacja jest dostępna na licencji Creative Commons. Uznanie autorstwa-Użycie niekomercyjne-Bez utworów zależnych 3.0 Polska. Pewne prawa zastrzeżone na rzecz autora. Zezwala się na wykorzystanie publikacji zgodnie z licencja - pod warunkiem zachowania niniejszej informacji licencyjnej oraz wskazania autora jako właściciela praw do tekstu. Treść licencji jest dostępna na stronie: http:// creativecommons.org/licenses/ by-nc-nd/ 3.0/pl/

Lingwistyka Stosowana 21: 1/ 2017, 175-186

\author{
Magdalena ZABIELSKA
}

Uniwersytet im. Adama Mickiewicza w Poznaniu

\title{
Medyczny opis przypadku w służbie lekarzom, studentom i pacjentom
}

\begin{abstract}
:
The medical case report in the service of doctors, students and patients

In this paper, a new generic development in the medical case report will be presented as a useful tool in the broadly understood medical context. A case report describes new diseases or their novel aspects, and its new interactive type additionally allows readers to comment on published cases and features patients' first person accounts. This development may become a useful tool in the teaching of medical English, especially in terms of terminology and frequently used expressions, in medical training, educating through case-based teaching, as well as in professional development, through incorporating the patient into professional communication and emphasising doctor's reflection.
\end{abstract}

\section{Wstęp}

Opis przypadku, będący gatunkiem medycznego dyskursu pisanego przeznaczonego dla fachowców, należy do najstarszych form komunikacji w medycynie. Raportowanie przypadków chorób u konkretnych pacjentów sięga czasów Starożytnego Egiptu (F.H. Garrison 1929), Starożytnych Chin (A. Kasim i wsp. 2009) czy Grecji (K.M. Hunter 1991: 93). O ile w tamtych czasach opisy te stanowiły jedyne źródło wiedzy medycznej, wraz z rozwojem medycyny, nowych sposobów diagnozowania i leczenia, znacznie straciły na znaczeniu (J.P. Vandenbroucke 2001: 333). Miało to związek ze zmianą paradygmatu w medycynie na ten oparty o dowody (ang. evidencebased medicine) (S. Kunt-Akbaş 2013), na skutek którego powstały nowe gatunki w komunikacji medycznej, np. artykuł naukowy. Ze względu na to iż te przedstawiały badania oparte na liczniejszych populacjach, później również z wykorzystaniem narzędzi statystycznych, zyskały one większe znaczenie w porównaniu do opisów przypadku, postrzeganych jako subiektywne raporty indywidualnych lekarzy. Ostatnio jednak można zaobserwować ponownie zainteresowanie gatunkiem (D.J. Pierson 2009: 1373; T. Nakamura i wsp. 2014; T. Nissen/ R. Wynn 2014), który dostosowuje się do zmian zachodzących w praktyce medycznej oraz, co za tym idzie, relacji lekarzpacjent, $\mathrm{z}$ tendencją do uwzględniania subiektywnej perspektywy pacjenta/ lekarza oraz szerokiego zastosowania w edukacji medycznej. Rezultatem tego ponownego zainteresowania są pojawiające kolejne modyfikacje gatunku, min. oparta na faktach 
(A. Jones-Harris 2003), zintegrowana (S. Reis i wsp. 2002), interaktywna (R. Smith 2008a, b), czy liczne serie o charakterze edukacyjnym (D.J. Pierson 2009).

Celem niniejszego artykułu przedstawienie nowej odmiany medycznego opisu przypadku jako narzędzia znajdującego wielorakie zastosowanie w szeroko pojętym kontekście medycznym. Najpierw zostanie zdefiniowany medyczny opisu przypadku jako gatunek tekstu specjalistycznego, uwzględniając jego charakter oraz strukturę. Następnie omówione zostanie tło dla modyfikacji, które zachodzą w tym gatunku, tj. zmiany $\mathrm{w}$ paradygmatach medycznych min. postrzegania choroby i roli pacjenta w procesie diagnozy i leczenia, oraz szersze zmiany w komunikacji w medycynie. Ostatnią częścią pracy będzie szczegółowe omówienie znaczenia medycznego opisu przypadku w szeroko pojętym kontekście medycznym, tj. w nauczaniu języka specjalistycznego, szkoleniu lekarzy oraz ich rozwoju zawodowym.

\section{Medyczny opis przypadku jako gatunek}

Opis przypadku ,jest mniej lub bardziej szczegółowym raportem dotyczącym objawów, badania fizykalnego, wyników badań obrazowych i laboratoryjnych, diagnozy, leczenia i odpowiedzi na nie, wreszcie możliwych komplikacji czy nietypowego zejścia choroby" (P. Czapiewski 2015). Pomimo iż każde fachowe czasopismo medyczne posiada swoje własne wytyczne co do struktury opisu przypadku regulujące jego długość, nazewnictwo części, etc. można jednak mówić o tzw. kanonicznej strukturze gatunku, która powtarza się w każdym opisie (por. M. Zabielska 2014). Medyczne opisy przypadku rozpoczynają się od Wstępu, zaznajamiającego czytelnika z tematyką, przypadkiem konkretnego pacjenta i z jego/ jej problemem. Następnie pojawia się Część główna, najbardziej rozbudowana część, zawierająca historię choroby pacjenta, wykonane badania, diagnozę, oraz opis przeprowadzonego leczenia. Opis przypadku kończy się Dyskusją/ konkluzjami, gdzie podane są rezultaty leczenia i ich znaczenie dla pacjenta (por. E. Rowley-Jolivet 2007: 185).

Jak wspomniano powyżej, pomimo kanonicznej struktury, którą można rozróżnić w każdym przypadku tego gatunku, w zależności od czasopisma i jego profilu, obecne są także inne odsłony, występujące w literaturze zarówno polsko- jak i anglojęzycznej: skrótowe opisy przypadku „Clinical photograph”, zawierające informacje o występowaniu danej choroby, całym procesie leczenia oraz Dyskusję i Wnioski w formie ciągłego tekstu, bez podziału na sekcje (Otolaryngology - Head and Neck Surgery); „Cardiovascular flashlights”, jednostronicowe opisy, zwracające uwagę czytelnika na kluczowe zagadnienia (European Heart Journal); „Diagnosis in oncology”, artykuły w formie tradycyjnego opisu przypadku, bez Wstępu, rozpoczynające się od przedstawienia pacjenta wraz z Omówieniem oraz Przegladem literatury (Journal of Clinical Oncology); i „Clinical problem solving”, artykuły podzielone na Quiz case, przybliżenie przypadku wraz z pytaniem o postawienie diagnozy przez czytelnika, oraz Diagnosis, rozpoznanie choroby i omówienie zagadnienia (Archives of Otolaryngology Head and Neck Surgery). W niektórych czasopismach opisy przypadków drukowane są w „Listach do redakcji” (ang. „Letter to the editor”) (np. Journal of Clinical Oncology). W polskojęzycznej literaturze nowatorskimi odmianami opisów przypadków 
mogą być „Studium przypadku” (ang. „Clinical vignette”), zawierające jedynie przedstawienie przypadku bez Omówienia (Kardiologia Polska), oraz dwujęzyczne opisy przypadków, składające się z rubryki w języku polskim oraz tłumaczenia w języku angielskim (Chirurgia Polska).

Wspomniane wyżej współczesne modyfikacje, takie jak oparta na faktach czy zintegrowana, które odzwierciedlają zmiany zachodzące w praktyce medycznej (por. G.P. Browman 1999: 1972), są już jednak bardziej znaczącymi ingerencjami w gatunek, wpływającymi na jego charakter i wydźwięk, co zostanie omówione i zilustrowane w kolejnej sekcji.

\section{Interaktywna odmiana medycznego opisu przypadku}

Wersja interaktywna (ang. interactive) została zainicjowana przez fachowe czasopismo British Medical Journal w roku 2003 (R. Smith 2008a, b; M. Murawska 2014). Tutaj pojedynczy opis przypadku miał formę serii trzech raportów poświęconych jednemu tematowi, składających się z Prezentacji przypadku (ang. Case presentation), przedstawiającej dany przypadek choroby i zapraszający czytelników do dyskusji, Postępów przypadku (ang. Case progress), opisujących przebieg leczenia, oraz Rezultatów leczenia (ang. Case outcome), podsumowujących wyniki podjętej terapii, a także dyskusję i wskazania do dalszych badań. Innowacyjność tej odmiany, jej tzw. interaktywność, miała podwójny charakter - możliwość komentowania na bieżąco prezentowanych kwestii oraz sekcja Perspektywa pacjenta (ang. Patient's perspective), pojawiająca się w ostatniej części, gdzie sam pacjent mógł wypowiedzieć się o swoich doświadczeniach $\mathrm{z}$ chorobą i leczeniem $\mathrm{w}$ formie pierwszoosobowej narracji. Tekst ten mógł być pisany przez samego pacjenta, w kooperacji z lekarzem lub, rzadziej, przez samego lekarza. Interaktywne opisy przypadku były zatem serią mniejszych opowieści autorstwa lekarzy, czytelników i pacjentów, dodatkowo o charakterze dynamicznym, gdyż dany wątek rozwijał się na przestrzeni trzech tekstów. Można powiedzieć, że interaktywna odmiana umożliwiła społeczności medycznej i innym czytelnikom „podzielenie się kwestiami dotyczącymi komunikacji z innych perspektyw, wzbogaconymi o wkład pacjenta" (E. Peile 2003: 1136; por. S. Biswas 2014). Projekt ostatecznie został jednak po pewnym czasie zakończony, głównie ze względu na jego czasochłonny charakter, jednak sama idea interaktywności jest nadal praktykowana. Komentarze czytelników dotyczące treści artykułów, szczególnie w formie postów pod elektronicznymi wersjami artykułów, są dziś nieodłącznym elementem publikacji fachowych, a włączanie perspektywy pacjenta jest rekomendowane przez wielu redaktorów czasopism (S. Biswas 2014).

W celu zilustrowania innowacyjności opisywanej odmiany, wybrano dwa poniższe fragmenty zaczerpnięte z sekcji Perspektywa pacjenta, obydwa odnoszące się do subiektywnej percepcji i doświadczeń leczonych. W pierwszym fragmencie, pacjent docenia możliwość zdecydowania, które z objawów jego/ jej choroby powinny być uwzględnione jako pierwsze oraz sam fakt zainteresowania się jego/ jej stanem zdrowia. Drugi z kolei przykład zawiera opis subiektywnych odczuć związanych ze stanem chorobowym oraz wyraz wdzięczności ze strony pacjenta. 
a) It was nice that I chose which symptoms were the most important to measure. This was a difficult pregnancy for me, and I was finding it difficult to cope with feeling ill and looking after my daughter. Even though the medication didn't work in the end, I don't regret doing the trial. It was helpful that someone took an interest in how I was feeling. BMJ2

b) It was a harrowing experience for me when I started balding and growing excessive hair all over my body. My fears increased as my friends and relatives started noticing a change in my voice. When the doctors told me I had a tumour, I felt my outcome was bleak. After the operation, my physical appearance improved, and my social life has returned to normal. I am grateful to the doctors for all they have done. CJ14

Wybór tematyki poruszanej przez pacjenta w specjalnie przeznaczonej dla niego sekcji leży całkowicie w jego/ jej gestii, jednak najczęściej podejmowane kwestie to: wpływ choroby na życie pacjenta poprzedzające leczenie, doświadczenia związane z samym leczeniem i jakość życia po nim, oraz relacje lekarz-pacjent (M. Murawska 2014).

\section{Tło dla modyfikacji gatunku}

Innowacyjność interaktywnych opisów przypadku jak i innych jego odmian ma swoje odzwierciedlenie w szerszych zmianach zachodzących w praktyce medycznej jak i szeroko rozumianej komunikacji o zdrowiu. Należy tu wspomnieć pojęcie tzw. Medycyny 2.0, która analogiczne do Sieci 2.0, oznacza iż dzięki internetowi wiedza medyczna nie jest dziś dostępna jedynie dla specjalistów ale również dla pacjentów, którzy, zanim zobaczą lekarza, mogą uzyskać istotne informacje na forach internetowych, blogach czy nawet od specjalisty udzielającego porad za pośrednictwem wybranej strony internetowej. Co więcej, pacjenci mogą też sami tworzyć materiały o tematyce medycznej i dzielić się nimi z innymi zainteresowanymi. Cytując za R.H. Jones (2013: 5), ,nie będąca już domeną ekspertów, informacja medyczna krąży swobodnie w prasie i mediach elektronicznych, dyskursie publicznym, i codziennych rozmowach laików, i jest stale reinterpretowana, przeformułowywana przemieszczając się z czasopism fachowych do relacji w gazetach, do mediów społecznościowych, do rozmów przy obiedzie". Interaktywna odmiana jest więc uwzględnieniem perspektywy pacjenta, tj. innej niż ta fachowa, i w pewien sposób współtworzona przez niego.

Warto tu również wspomnieć o tzw. paradygmatach w praktyce medycznej które kształtują konceptualizację choroby oraz roli pacjenta w procesie diagnozy i leczenia. W przypadku modelu biomedycznego (ang. biomedical model) można mówić o chorobie jako pewnego rodzaju usterce w prawidłowym funkcjonowaniu ciała - maszyny, którą powinna być usunięta. W tym celu należy odnaleźć obiektywne objawy schorzenia i je wyeliminować (por. D.T. Wade/ P.W. Halligan 2004). W modelu tym nie ma miejsca na indywidualne doświadczenie choroby oraz uwzględnienie jej psychologicznych i społecznych aspektów, co z kolei znalazło się w modelu zorientowanym na pacjenta (ang. patient-centred model), który był bezpośrednią reakcją na model biomedyczny. Zorientowanie na pacjenta oznacza innymi słowy iż nie można 
zdiagnozować pacjenta bez uwzględnienia jego/ jej subiektywnej percepcji stanu chorobowego (M. Balint 1956). Kolejny krok to tzw. wsparcie pacjenta (ang. patient advocacy). $\mathrm{O}$ ile $\mathrm{w}$ modelu zorientowanym na pacjenta dobro samego pacjenta zostało wzięte pod uwagę, we wsparciu chodzi o zwiększenie znaczenia jego/ jej roli w procesie diagnozy i leczenia (por. M.B. Gilkey i wsp. 2008). Cytując za C. Mattingly (1998: 74), wsparcie pacjenta to ,nie tylko co się dzieje z pacjentem i jak można temu zaradzić, ale również jak można zaangażować pacjenta w ten proces”. W kontekście praktyki medycznej paradygmat ten zaleca większą swobodę decyzyjną po stronie pacjenta, podczas gdy w kontekście komunikacji, np. fachowej, odzwierciedleniem tego modelu może być włączenie perspektywy pacjenta $\mathrm{w}$ formie jego/ jej narracji w publikacji przeznaczonej dla fachowców.

\section{Znaczenie opisu przypadku w szeroko pojętym kontekście medycznym}

W tej części zostanie szczegółowo omówione znaczenie medycznego opisu przypadku jak również jego interaktywnej odmiany w szeroko pojętym kontekście medycznym, tj. nauki języka specjalistycznego, szkoleniu lekarzy oraz w ich rozwoju zawodowym, przechodząc tym sposobem z perspektywy mikro do perspektywy makro.

\subsection{Nauczanie specjalistycznego języka medycznego}

Medyczne opisy przypadku, włączając ich odmianę interaktywną, są bez wątpienia wartościowym materiałem w nauczaniu medycznego języka specjalistycznego, będącymi dobrym przykładem dyskursu specjalistycznego, np. leksyki jak również cech strukturalnych. W odniesieniu do pierwszego elementu, istotnymi są tu terminologia i kolokacje, których opanowanie stanowi jeden z etapów w socjalizacji do dyskursu fachowego. Tego typu jednostki językowe zostały zidentyfikowane w gatunkowej analizie opisów przypadku autorstwa R. Helán (2012) oraz bardziej szczegółowym badaniu portretu pacjenta w tym gatunku (M. Zabielska 2014; M. Zabielska/ M. Żelazowska 2016) oraz w korpusowym badaniu biomedycznego języka w tekstach naukowych autorstwa D. Salazar i wsp. (2013). Trzy pierwsze badania zwracają uwagę na kolokacje charakterystyczne dla typów informacji pojawiających się w poszczególnych częściach opisów przypadku, np. problem z którym zgłasza się pacjent (Wstęp), por. (c-d) poniżej (M. Zabielska 2014; M. Zabielska/ M. Żelazowska 2016); historia, badanie fizykalne/ testy diagnostyczne, diagnoza i leczenie (Część główna), por. (e) (M. Zabielska 2014; M. Zabielska/ M. Żelazowska 2016), (f-g) (R. Helán 2012; M. Zabielska/ M. Żelazowska 2016) i (h) (M. Zabielska 2014; M. Zabielska/ M. Żelazowska 2016); oraz omówienie przypadku (Dyskusja/ konkluzje), por. (i) (M. Zabielska 2014; M. Zabielska/ M. Żelazowska 2016) i (j) (D. Salazar i wsp. 2013; M. Zabielska/ M. Żelazowska 2016). Poniżej zostały podane charakterystyczne kolokacje z poszczególnych części opisów przypadku wraz z przykładami, zaczerpniętymi zarówno z anglojęzycznych (R. Helán 2012; D. Salazar i wsp. 2013; M. Zabielska 2014) jak i polskich opisów przypadku (M. Zabielska/ M. Żelazowska 2016). 
c) pacjent zgłosił się do medycznej placówki z konkretnymi symptomami

Kobieta (41 lat), zgłosiła się do lekarza z powodu trwajacych od trzech tygodni dolegliwości bólowych podbrzusza oraz stanów podgoraczkowych. PAP18 (M. Zabielska/ M. Żelazowska 2016)

d) pacjent uskarżał się na konkretne symptomy

She had complained of worsening holocephalic headache. LA14 (M. Zabielska 2014)

e) historia pacjenta

His medical history was negative for underlying illnesses. JA2 (M. Zabielska 2014)

Dziewczynka do tej pory nie byta nigdy hospitalizowana, nie miała takze wykonywanych w przeszłości badań ogólnych moczu. PM1 (M. Zabielska/ M. Żelazowska 2016)

f) w badaniu

On examination, the 14-month-old patient was found to be afebrile and tachypneic... JMCR 3/ 1/ 6495 (R. Helán 2012)

W badaniu przedmiotowym zwracaty uwagę: niski wzrost, liczne zmiany skórne o typie plam ,kawy z mlekiem”, nerwiakowtókniaki oraz piegi w okolicy pachwin i pach (ryc. 1, 2). NT1 (M. Zabielska/ M. Żelazowska 2016)

g) zdiagnozowano

A clinical diagnosis of left hamstring tendinitis was made. JMCR 4/ 1/ 76 (R. Helán 2012)

U chorej rozpoznano gruźlicę otrzewnej z przejściem procesu na narząd rodny. PAP18 (M. Zabielska/ M. Żelazowska 2016)

h) zastosowano u pacjenta

The patient was treated with ketoconazole alone and then in combination with the glucocorticoid antagonist mifepristone, but the drugs did not control the hypercortisolism. NEJM10 (M. Zabielska 2014)

Zastosowano leczenie skojarzone rifampicyna $(0,6 \mathrm{~g} / \mathrm{d}$.), izoniazydem $(0,3 \mathrm{~g} / \mathrm{d}$.) $i$ pyrazynamidem $(1,5 \mathrm{~g} / \mathrm{d}$.), uzyskując wygojenie zmian skórnych $i$ normalizację rozmiarów węztów chłonnych szyi. PAP17 (M. Zabielska/ M. Żelazowska 2016)

i) choroba zdiagnozowana u pacjenta

In 1994, splenomegaly was documented in a 72-year-old woman from the Greek island of Karpathos during a routine examination (her first in many years). NEJM2 (M. Zabielska 2014) 
Wystapienie u chorego z NF1 nadciśnienia tętniczego, zwłaszcza o ciężkim przebiegu i opornego na leczenie farmakologiczne stanowi bezwzgledne wskazanie do przeprowadzenia badań w kierunku występowania guza chromochłonnego. NT1 (M. Zabielska/ M. Żelazowska 2016)

j) w tym przypadku/ w opisywanym przypadku

In the present case in which SAC6 is overexpressed, these bars likely reflect an increase in actin filament cross-linking activity. G5 (D. Salazar i wsp. 2013)

Opisany przypadek chorego z obustronnymi guzami chromochłonnymi i nerwiakowłókniakowatościa typu 1 należy omówić z kilku względów. NT1 (M. Zabielska/ M. Żelazowska 2016)

Poza wyżej wymienionymi pracami, wśród badań słownictwa specjalistycznego z dziedziny medycyny można wskazać również, w zakresie języka angielskiego, P. Mungra i T. Canziani (2013) z ich listą słownictwa z dziedziny medycyny klinicznej sporządzoną na podstawie ilościowej analizy słownictwa używanego w historiach chorób (w zakresie języka angielskiego), Studencki słownik terminoelementów angielskiego języka medycyny, przygotowany przez Koło Naukowe BAJT z Katedry Języków Specjalistycznych UW, oraz Lekarski poradnik językowy (w zakresie języka polskiego). Tego typu badania mogą być również wykorzystywane jako gotowe listy słownictwa/ glosariusze podczas zajęć z terminologii medycznej, oprócz materiałów autentycznych, opisywanych w niniejszej pracy.

\subsection{Szkolenie lekarzy}

W kontekście szkolenia lekarzy, na uwagę zasługuje coraz powszechniejsze zastosowanie medycznych opisów przypadku w seriach w fachowych czasopismach naukowych prezentujących przykładowe „scenariusze” przypadków rzadko występujących oraz trudnych do zdiagnozowania lub wyleczenia, w celu sprawdzenia wiedzy czytelników. Można przytoczyć tu następujące przykłady: „Lesson of the Week” (British Medical Journal), „Interpretation Corner” (European Radiology), „Case Challenge” (Medscape) oraz „Pulmonary and Critical Care Pearls” (Chest), których nazwy bardzo często odzwierciedlają charakter prezentowanych problemów. Według O. Yitschaky i wsp. (2011: 180), umożliwiają one ,większy wgląd w nietypowe zagadki napotykane przez specjalistów w ich codziennej praktyce".

Wyżej wymienione zastosowanie wskazuje z kolei na przypadek jako ,podstawową jednostkę rozumowania w medycynie" (K.M. Hunter 1991: 51). Jak zauważa przecież R. Smith (2008a: 1), „,każde nowe schorzenie - czy jest to AIDS, SARS, czy inna pojawiająca się choroba - zaczyna się od pojedynczego przypadku”. W tym kontekście, o podstawowej roli przypadku w medycynie świadczy również obecność licznych gatunków opartych na przypadkach, np. zapis przypadku czy prezentacja przypadku. W odniesieniu do drugiej pozycji, również studenci medycyny od samego początku wdrażani są w myślenie w kategoriach przypadków (S. Bhattacharrya i wsp. 2014; M.J. Fillyaw 2011; C.J. Good 2009) - opisywania przypadków chorób, które 
napotykają w swojej praktyce, leczenia przypadków chorób u swoich pacjentów, oraz tzw. opracowania przypadku, umiejętności jakiej studenci uczą się podczas obchodu szpitalnego, gdzie muszą zaprezentować profesorowi i innym osobom obecnym konkretne przypadki chorób u leżących na oddziale pacjentów, zdiagnozować je i zaproponować leczenie. Istotną w tego typu prezentacji jest nie tylko odpowiednio zastosowana wiedza medyczna ale również kolejność przedstawionych faktów oraz użyte środki językowe. „Poprzez takie działanie, autorzy uczą się, jak przeprowadzać analizę literatury pod kątem konkretnych informacji, wyjaśniać historię choroby, prezentować umiejętności analizy, podawać racjonalne wyjaśnienia dla wyników" (S.B. Bavdekar/ S. Save 2015: 45). Pozwala im to również na zrozumienie funkcjonowania całego organizmu i jego zaburzeń w procesach chorobowych (J. Engelberg 1992). Jest to z kolei przykład tzw. nauczania opartego na przypadku (ang. problembased earning) (H.S. Barrows 1990; C. Frederiksen 1999).

\subsection{Rozwój zawodowy}

W przypadku trzeciego zastosowania, tj. w kontekście rozwoju zawodowego, należy odwołać się konkretnie do sekcji Perspektywa pacjenta z interaktywnej odmiany medycznego opisu przypadku. Sam fakt iż subiektywne odczucia pacjenta stają się integralną częścią fachowej publikacji świadczy o znacznym zwiększeniu znaczenia relacji osoby leczonej jako potencjalnie istotnego źródła informacji medycznej. Dla pacjenta z kolei możliwość podzielenia się historią choroby może mieć znaczenie terapeutyczne (P. Haidet/ D. Paterniti 2003). Po stronie lekarza lektura tego typu opowieści może też skłaniać do refleksji nad własnym zawodem i relacjami z pacjentem (F. Davidoff 1996: 270). Należy tutaj podkreślić iż, jak już wcześniej wspomniano, włączenie narracji pacjenta w dyskurs fachowy może być uważane za odzwierciedlenie modelu wsparcie pacjenta, który ogólnie postulując zwiększenie roli decyzyjnej pacjenta, może być też realizowany na poziomie tekstu i komunikacji poprzez zaproszenie osoby leczonej do uzupełnienia opisu przypadku.

\section{Konkluzje}

Celem niniejszej pracy było zaprezentowanie interaktywnej odmiany medycznego opisu przypadku jako przykładu gatunku dyskursu specjalistycznego będącej odzwierciedleniem zmian zachodzących w praktyce medycznej - wsparcie pacjenta i Medycyna 2.0. Uwzględnienie wypowiedzi leczonego o subiektywnym doświadczeniu choroby, nowy element $\mathrm{w}$ odmianie interaktywnej, jest traktowane jako forma zwiększenia roli pacjenta w procesie diagnozy i leczenia, analogiczne do jego/ jej większej decyzyjności w kontekście relacji lekarz-pacjent. Interaktywne opisy przypadku wpisują się także w kontekst zjawiska tzw. Medycyny 2.0., gdyż oddając głos również pacjentowi, otwierają wiedzę medyczną na inne perspektywy niż ta należąca jedynie do specjalisty oraz w pewien sposób pozwalają na jej współtworzenie przez leczonego. W drugiej części artykułu gatunek ten ogólnie oraz jego odmiana interaktywna zostały omówione jako użyteczne narzędzie znajdujące zastosowanie w sze- 
roko pojętym kontekście medycznym: 1) w nauczaniu języka angielskiego medycznego, jako przykład dyskursu specjalistycznego; 2) w szkoleniu lekarzy, jako przykład nauczania opartego na przypadku poprzez prezentację wyjątkowo trudnych przypadków chorób; 3) oraz w rozwoju zawodowym, tu szczególnie w kontekście interaktywnej odmiany, poprzez uwzględnienie perspektywy pacjenta oraz podkreślenie refleksji nad zawodem ze strony lekarza.

\section{Bibliografia}

Balint, M. (1956), The doctor, his patient and the illness. London.

Barrows, H.S. (1990), The pedagogical importance of a skill central to clinical practice, (w:) Medical Education, 24, 3-5.

Bavdekar, S.B./ S. Save (2015), Writing case reports: Contributing to practice and research, (w:) Journal of the Association of Physicians of India, 63, 44-48.

Bhattacharrya, S./ J. Miller/ A.H. Ropper (2014), A special group: With ethnographic perspective, (w:) Annals of Neurology, 76, 484-486.

Biswas, S. (2014), Beginner's guide to writing case reports. ( www.juniordr.com/ index.php/ research/ writing-case reports.html; pobrano 1.8.2014).

Browman, G.P. (1999), Essence of evidence-based medicine: A case report, (w:) Journal of Clinical Oncology, 17, 1969-1973.

Czapiewski, P. (2015), Specyfika artykulu case report, (w:) Ł. Budyńko/ P. Waszak (red.), Pomysł - badanie - publikacja. Poradnik naukowy dla studentów kierunków medycznych. Gdańsk, 283-288.

Davidoff, F. (1996), On being a patient, (w:) Annals of Internal Medicine, 124 (2), 269-270.

Engelberg, J. (1992), Complex medical case histories as portals to medical practice and integrative, scientific thought, (w:) American Journal of Physiology, 263, 4554.

Fillyaw, M.J. (2011), Case report writing in a doctor of physical therapy education program: A case study, (w:) Journal of the Scholarship of Teaching and Learning, $11(1), 139-154$.

Frederiksen, C. (1999), Learning to reason through discourse in a problem-based learning group, (w:) Discourse Processes, 27, 135-160.

Garrison, F.H. (1929), An introduction to the history of medicine. Philadelphia.

Gilkey, M.B./ J.-A.L. Earp/ E.A. French (2008), What is patient advocacy?, (w:) J.A.L. Earp/ E.A. French/ M.B. Gilkey (red.), Patient Advocacy for Health Care Quality: Strategies for Achieving Patient-centred Care. Boston, 3-28.

Good, C.J. (2009), Student-generated case reports, (w:) Journal of Chiropractic Education, 23, 165-173.

Haidet, P./ D. Paterniti (2003), Building a history rather than taking one. A perspective on information sharing during the medical interview, (w:) Archives of Internal Medicine, 163, 1134-1140.

Hunter, K.M. (1991), Doctors' stories. The narrative structure of medical knowledge. Princeton. 
Helán, R. 2012. Analysis of published medical case reports: Genre-based study. $\mathrm{PhD}$ thesis, Masaryk University, Brno.

(http:/ / is.muni.cz/ th/ 18899/ ff_d/ DISSERTATION_-_ROBERT_HELAN.pdf; pobrano 2.6.2014).

Jones, R.H. (2013), Health and risk communication: An applied linguistic perspective. London.

Jones-Harris, A. (2003), The evidence-based case report: A resource pack for chiropractors, (w:) Clinical Chiropractic, 6, 73-84.

Kasim, N.H.A./ B.J.J. Abdullah/ J. Manikam (2009), The current status of the case report: Terminal or viable?, (w:) Biomedical Imaging and Intervention Journal, 5, e4. (URL

www.ncbi.nlm.nih.gov/ pmc/ articles/ PMC3097753/ pdf/ biij-05-e4.pdf; pobrano 2.6.2015).

Kunt-Akbas, S. (2013), A genre analysis of medical case reports. (www.academia.edu/2452076/A_Genre_Analysis_of_Medical Case_Reports; pobrano 1.6.2015).

Lekarski poradnik językowy. (http://lpj.pl/ ; pobrano 1.6.2015).

Mattingly, C. (1998), Healing dramas and clinical plots. The narrative structure of experience. Cambridge.

Mungra, P./ T. Canziani (2013), Lexicographic studies in medicine: Academic word list for clinical case histories, (w:) Ibérica, 25, 39-62.

Murawska, M. (2014), Interactive case reports - a case in point, (w:) H. Lankiewicz/ E. Wąsikiewicz-Firlej (red.), Languaging Experiences: Learning and Teaching Revisited. Newcastle upon Tyne, 95-115.

Nakamura, T./ H. Igarashi/ T. Ito/ R.T. Jensen (2014), Important of case-reports/ series, in rare diseases: Using neuroendocrine tumors as an example, (w:) World Journal of Clinical Cases, 16 (2), 11, 608-613.

Nissen, T./ R. Wynn (2014), The clinical case report: A review of its merits and limitations, (w:) BMC Research Notes 7, 264. (http://bmcresnotes.biomedcentral.com/ articles/ 10.1186/ 1756-0500-7-264; pobrano 4.5.2015).

Peile, E. (2003), Commentary: More to be learnt from the discussion than the diagnosis, (w:) British Medical Journal, 326, 1136.

Pierson, D.J. (2009), How to read a case report (or teaching case of the month, (w:) Respiratory Care, 54 (10), 1372-1378.

Reis S./ D. Hermoni/ P. Livingstone/ J. Borkan (2002), Integrated narrative and evidence based case report: Case report of paroxysmal atrial fibrillation and anticoagulation, (w:) British Medical Journal, 325, 1018-1020.

Rowley-Jolivet, E. (2007), A genre study of If in medical discourse, (w:) K. Fløttum (red.), Language and Discipline Perspectives on Academic Discourse. Newcastle, 184-214.

Salazar, D./ I. Verdgauer/ N.J. Laso/ E. Commeles/ E. Castano/ J. Hilferty (2013), Formal and functional variation of lexical bundles in biomedical English, (w:) I. Verdaguer/ N.J. Laso/ D. Salazar (red.), Biomedical English. A Corpusbased Approach. Amsterdam, 39-53. 
Smith, R. (2008a), Why do we need Cases Journal, (w:) Cases Journal 1, 1. (www.ncbi.nlm.nih.gov/ pmc/ articles/ PMC2423473/ pdf/ 1757-1626-1-1.pdf; pobrano 1.6.2015).

Smith, R. (2008b), The policies of Cases Journal, (w:) Cases Journal 1, 2. (www.casesjournal.com/ content/ 1/ 1/2; pobrano 1.6.2015).

Studencki słownik terminoelementów angielskiego języka medycyny, przygotowany przez Koło Naukowe BAJT, Katedra Języków Specjalistycznych UW (2008), (w:) Debiuty Naukowe, 2, 117-176.

Vandenbroucke, J.P. (2001), In defence of case reports and case series, (w:) Annals of Internal Medicine, 134/ 4, 330-334.

Wade, D.T./ P.W. Halligan (2004), Do biomedical models of illness make for good healthcare systems?, (w:) British Medical Journal, 329, 1398-1401.

Yitschaky, O./ M. Yitschaky/ Y. Zadik (2011), Case report on trial: Do you, doctor, swear to tell the truth, the whole truth and nothing but the truth?, (w:) Journal of Medical Case Reports, 5, 179-180.

Zabielska, M. (2014), Searching for the patient's presence in medical case reports. Frankfurt a. M.

Zabielska, M./ M. Żelazowska (2016), Spójność tekstu specjalistycznego a obraz pacjenta $w$ medycznym opisie przypadku - kontynuacja badania, (w:) M. Górnicz/ M. Kornacka (red.), Spójność tekstu specjalistycznego (2). Warszawa, 112-124.

\section{Teksty źródłowe}

BMJ2 Harker, N./ A. Montgomery/ T. Hafey (2004), Treating nausea and vomiting during pregnancy: Case outcome, (w:) British Medical Journal 328, 503.

CJ14 Salim, S./ G. Palamaner Subash Shantha/ A.D. Patel/ A.A. Kumar/ P. Ganeshram/ N. Mehra/ A.G. Rajan/ T. Joseph/ L. Sudhakar (2009), Virilising ovarian steroid cell tumour in a 40 year old South Indian female: A case report, (w:) Cases Journal 2, 7521. (http://casesjournal.com/ casesjournal/ article/ view/ 7521; pobrano 3.9.2012).

G5 Sandrock, T.M./ S.M. Brower/ K.A. Toenjes/ A.E. Adams (1995), Suppressor analysis of fimbrin (Sac6p) overexpression in yeast, (w:) Genetics, 151 (4), 12871297.

JA2 Mak, R./ G.C. Gray/ M.D. Malasig/ L.N. Binn/ L.V. Asher/ D. Cute/ S.C. Kehl/ B.E. Dunn/ J. Zablocki/ A.J. Yund (2001), Two fatal cases of adenovirus-related illness in previously healthy young adults - Illinois, 2000, (w:) Journal of American Medical Association, 286, 553-556.

JMCR 3/ 1/ 6495 Smith, J.C./ E. Cohen (2009), Beta-2-transferrin to detect cerebrospinal fluid pleural effusion: A case report, (w:) Journal of Medical Case Reports, 3, 6495. (www.ncbi.nlm.nih.gov/ pmc/ articles/ PMC2726474/pdf/ 1752-19470003-0000006495.pdf; pobrano 3.9.2014).

JMCR 4/ 1/ 76 Douglas, R.J. (2010), Palpitations following regular Ibuprofen dosing in a 13-year-old girl: A case report, (w:) Journal of Medical Case Reports, 4, 76. (www.ncbi.nlm.nih.gov/pmc/articles/PMC2838914/pdf/1752-1947-4-76.pdf; pobrano 3.9.2014). 
LA14 Lindley-Jones, M./ D. Lewis/ J.L. Southgate (2004), Recurrent tetanus, (w:) Lancet, 363, 2048.

NEJM2 Vinetz, J.M./ J. Li/ T.F. McCutchan/ D.C. Kaslow (1998), Plasmodium malariae infection in an asymptomatic 74-year-old Greek woman with splenomegaly, (w:) New England Journal of Medicine, 338, 367-371.

NEJM10 Arioglu, E./ J. Doppman/ M. Gomes/ D. Kleiner/ D. Mauro/ C. Barlow/ D.A. Papanicolaou (1998), Cushing's syndrome caused by corticotropin secretions by pulmonary tumorlets, (w:) New England Journal of Medicine, 339 (13), 883-886.

NT1 Pęczkowska, M./ A. Kubaszek/ H. Janaszek-Sitkowska/ E. Florczak/ M. Kabat/ M. Otto/ A. Okruszko/ J. Szmidt/ A. Januszewicz (2006), Chory z obustronnym guzem chromochłonnym i nerwiakowłókniakowatościa typu 1 - opis przypadku, (w:) Arterial Hypertension, 10 (4), 294-300.

PAP17 Owczarek, W./ T. Targowski/ K. Łebkowska/ E. Paluchowska (2009), Gruźlica węzłów chłonnych szyi z ognisiem gruźlicy rozpływnej - opis przypadku, (w:) Pneumonologia i Alergologia Polska, 77, 417-421.

PAP18 Zamłyński, J./ A. Olejek/ E. Oleś/ K. Stęplewska/ A. Krzywiecki/ G. Myrcik/ P. Bodzek/ M. Paliga-Żytniewska/ A. Gajewska (2009), Gruźlica otrzewnej czy rak jajnika - trudności diagnostyczne. Opisy dwóch przypadków, (w:) Pneumonologia i Alergologia Polska, 77, 422-428.

PM1 Benedyk, A./ A. Blumczyński/ J. Kowalewska/ D. Ostalska-Nowicka/ J. Zachwieja (2014), Ostre klębuszkowe zapalenie nerek u dziewczynki z rodzinnym zespotem Alporta - opis przypadku. (www.PrzypadkiMedyczne.pl; pobrano 1.6.2015). 